\title{
CIENCIA Y MORAL EN LA PREVENCIÓN DE LAS ENFERMEDADES VENÉREAS. LA SOCIEDAD MEXICANA DE PROFILAXIS SANITARIA Y MORAL, 1908-1923
}

\author{
María del Carmen Zavala Ramírez \\ Doctora en Historia, El Colegio de México \\ karmenzavala@gmail.com
}

Recibido: 29 septiembre 2015; Aceptado: 1 julio 2016.

Cómo citar este artículo/Citation: Zavala Ramírez, María del Carmen (2016), "Ciencia y moral en la prevención de las enfermedades venéreas. La Sociedad Mexicana de Profilaxis Sanitaria y Moral, 1908-1923", Asclepio, 68 (2): p157. doi: http://dx.doi.org/10.3989/ asclepio.2016.29

RESUMEN: La Sociedad Mexicana de Profilaxis Sanitaria y Moral fue fundada en 1908 con el propósito de luchar contra las enfermedades venéreas. A diferencia de iniciativas anteriores de prevención que se centraban en el control sanitario de la prostitución, la Sociedad promovió la creación de dispensarios para la atención médica de los enfermos, así como la difusión de conocimientos por medio de conferencias y de propaganda impresa. Este artículo analiza las ideas que dieron lugar a la fundación de la Sociedad, los principales mensajes que buscaba difundir, los obstáculos y las críticas que enfrentó, y las causas que la llevaron a su disolución en 1923. El artículo muestra que la ciencia y la moral fueron dos elementos centrales que la Sociedad buscó promover, pues sus integrantes asumieron que las enfermedades venéreas eran un problema sanitario y moral, que debía prevenirse con el control de la voluntad y las pasiones, y llegado el caso, tratarse con la ayuda de médicos calificados.

PALABRAS CLAVE: enfermedades venéreas; propaganda; ciencia; moral.

\section{SCIENCE AND MORALITY IN THE PREVENTION OF VENEREAL DISEASES.} THE MEXICAN SOCIETY FOR SANITARY AND MORAL PROPHYLAXIS, 1908-1923

ABSTRACT: The Mexican Society for Sanitary and Moral Prophylaxis was founded in 1908 for the purpose of fighting against venereal diseases. Unlike previous prevention initiatives that focused on sanitary control of prostitution, the Society promoted the creation of dispensaries for medical care for the sick, and the dissemination of knowledge through lectures and printed propaganda. This article analyzes the ideas that led to the founding of the Society, the main messages which it sought to spread, obstacles and criticism it faced, and the causes that led to its dissolution in 1923. The article shows that science and morality were two core elements that the Society sought to promote, since its members assumed that venereal diseases concerned to public health and morals, and that they could be prevented by the control of the will and passions, and if necessary, treated with the help of qualified physicians.

KEYWORDS: venereal diseases; propaganda; science; moral. 


\section{INTRODUCCIÓN}

A partir de mediados del siglo XIX las enfermedades venéreas llamaron cada vez más la atención de médicos alrededor del mundo ${ }^{1}$. La sífilis y la gonorrea provocaron miedos y angustias debido a que fueron asociadas con la degeneración de la raza. Aun cuando no había estadísticas precisas, la percepción de numerosos médicos era que estas enfermedades iban en aumento. Desde mediados del siglo XIX la reglamentación de la prostitución había sido del principal medio por el que se buscó prevenir la propagación de las enfermedades venéreas. Con el cambio de siglo llegaron a México ideas novedosas sobre los medios de prevención. La educación de la población en general y la propaganda antivenérea se incorporaron al repertorio médico preventivo mexicano.

Los esfuerzos por difundir conocimientos útiles para la prevención de las enfermedades venéreas entre la población mexicana iniciaron en los primeros años del siglo XX. Entonces, el «inteligente y laborioso" médico Andrés Benavides daba conferencias y publicaba el periódico La Espirila en la ciudad de Toluca (Landa, 1925, p.29) ${ }^{2}$. Aunque Benavides contó con el apoyo de las autoridades estatales, la iniciativa al parecer fue más personal que producto de un proyecto institucional.

Algunos años después, comenzaron las labores de propaganda de la Sociedad Mexicana de Profilaxis Sanitaria y Moral en la ciudad de México. Esta se propuso llevar conocimientos útiles que, basados en la ciencia y la moral, impidieran la propagación de las enfermedades venéreas.

\section{LA FUNDACIÓN DE LA SOCIEDAD MEXICANA DE PROFILAXIS}

La Sociedad Mexicana de Profilaxis Sanitaria y Moral de las Enfermedades Venéreas fue inaugurada el 25 de julio de 1908 por iniciativa de Jesús González Urueña, un médico dermatólogo que hacía parte de la Academia Nacional de Medicina (ANM). En diciembre de 1907 González Urueña presentó ante la Academia su trabajo titulado "Sífilis hereditaria tardía» (González, 1908, pp. 307-314). En él mostró estadísticas del Consultorio Central de la Beneficencia Pública desde febrero de 1905 hasta noviembre de 1907. Los resultados eran preocupantes: de un total de 7, 272 enfermos de la piel, 1,408 presentaron manifestaciones sifilíticas. Esto es, casi el $20 \%$ de los pacientes del Consultorio tenía sífilis.
Las estadísticas del Consultorio difícilmente podrían generalizarse, pues consideraban sólo a los pacientes del Consultorio, y entre ellos, sólo a los enfermos de la piel. Aun así, las enfermedades venéreas parecían amenazantes. A decir de González Urueña, los sifilíticos se convertían «por su ignorancia y por su descuido, en vectores de un mal, que es verdadera plaga social». A ellos se sumaba una «inmensa legión de los ignorados», que no figuraban en las estadísticas, pero que «todos los presentimos, todos los suponemos, y son tan reales como los otros» (González, 1908, p. 313). Por ello, el valor de estos datos no radicaba tanto en lo que mostraban, sino en lo que sugerían, es decir, la presencia de enfermos venéreos no diagnosticados y sin tratamiento que propagaban el mal con facilidad.

A fin de evitar que la «plaga social» continuara extendiéndose, González Urueña sugirió la fundación de una sociedad de profilaxis sanitaria y moral, dependiente de la ANM. Aunque el Consejo Superior de Salubridad (CSS) era la institución encargada de la "administración del servicio sanitario» (Código Sanitario, 1903) era, según González Urueña, la ANM la que debía tomar la iniciativa en las acciones para prevenir las enfermedades venéreas, pues «nadie podrá patrocinarlas con mayores seguridades de buen éxito que la Academia» (González, 1908, p. 313). El CSS tenía jurisdicción en el Distrito y Territorios Federales, en puertos y en fronteras (art. 5, Código Sanitario, 1903), y había llevado a cabo importantes campañas para prevenir enfermedades como la fiebre amarilla, la peste, el cólera, o la viruela. (Carrillo, 2008, pp. 21-256; Carrillo, 2005, pp. 10491103; Carrillo, 2002, p. 69; Zavala, 2007, pp. 39-88). En cuanto a las enfermedades venéreas, el CSS había participado en la reglamentación y el control sanitario de la prostitución, pero no desarrollaba actividades de propaganda como las que proponía llevar a cabo la Sociedad Mexicana de Profilaxis.

Aun si la ANM no era la rectora de las políticas sanitarias, tuvo el reconocimiento y el apoyo del gobierno mexicano. Desde 1877 la ANM contó con una partida de 5,000 pesos aprobada por la Cámara de Diputados y en 1887 obtuvo el título de «Nacional» (Rodríguez, 2013, pp. 572-5731). Entre sus integrantes estuvieron reconocidos médicos de distintas partes del país y algunos de ellos formaron parte también de la administración sanitaria. Por ello, González Urueña no dudó en afirmar que la ANM debía dirigir acciones para la prevención de enfermedades venéreas.

La ANM designó una comisión encargada de estudiar la mejor manera de llevar a cabo la lucha 
antivenérea en México. La comisión quedó integrada por Jesús González Urueña, Francisco Bulman y Aristeo Calderón, quienes entregaron su dictamen el 11 de marzo 1908. Uno de los objetivos de dicha comisión era saber si en "las naciones más cultas» se consideraba o no inmoral la lucha antivenérea. Por ello, hicieron un repaso de las acciones realizadas en Alemania, Austria, Bélgica, Estados Unidos, Francia, Grecia, Inglaterra, Italia, Suecia y Uruguay. La comisión encontró que en algunos lugares como Alemania (1902), Nueva York (1905), Austria (1907) y Francia (1901) se fundaron sociedades para la prevención de las enfermedades venéreas. Además, en otras partes del mundo también se llevaban a cabo acciones para impedir la propagación de dichos males y combatir la prostitución: en España se formó una asociación contra la trata de blancas, en Uruguay se reglamentó la prostitución y se difundió propaganda antivenérea, en Atenas se aprobaron leyes de enfermedades contagiosas, entre ellas las venéreas, y en Suecia se discutió un proyecto para combatir las enfermedades venéreas. También hubo propaganda en Londres y Roma («Dictamen», 1908, p. 3).

Como pudo constatar la comisión designada, la propagación de las enfermedades venéreas era una preocupación presente alrededor del mundo. Esto quedó de manifiesto en 1899 con la Conferencia Internacional de Enfermedades Venéreas celebrada en Bruselas, que dio por resultado la formación de la Sociedad Internacional de Profilaxis Sanitaria y Moral (Corbin, 1990, p. 265). Una Segunda Conferencia tuvo lugar en la misma ciudad en 1902, y a ella asistió el sifilógrafo Ricardo Cicero en representación de México (Cicero, 1925, p. 226).

En América Latina también hubo iniciativas nacionales e internacionales para la prevención de las enfermedades venéreas, que fueron conocidas en la ANM. En Brasil (1901) y Argentina (1907) fueron creadas sociedades de profilaxis sanitaria y moral, sólo que esta última se desintegró apenas unos tres o cuatro meses después de haberse constituido debido a la "falta de apoyo» (Coni, 1922, p. 13). Otro gran esfuerzo en la lucha antivenérea en el continente fue la Liga Latinoamericana contra la Avariosis. Esta fue creada en 1907 en el marco del Tercer Congreso Médico Latinoamericano celebrado en Montevideo y tuvo en su dirección a un par de médicos destacados: el argentino Emilio Coni como presidente, y José Brito Foresti de Uruguay como secretario (Verano, 1922, p. 54). Coni renunció a la presidencia de la Liga Latinoamericana en 1913, la cual desapareció «prematura- mente» (Veronelli, 2004, p. 333). A partir de las fuentes consultadas, no es clara cuál fue la participación de los médicos mexicanos en esta Liga, lo cierto es que estuvieron al tanto de sus labores. El mismo doctor Coni fue socio de la ANM de México desde 1887, y a partir de 1907, socio honorario (Viesca, 2014, p. 78).

La comisión de la ANM encargada de estudiar cómo llevar a cabo la lucha antivenérea concluyó que había un «inmenso vacío» en México y que era pertinente que se fundara una sociedad de profilaxis sanitaria y moral, como las que se habían fundado en otros países («Dictamen», 1908, p. 3). La Sociedad Francesa de Profilaxis Sanitaria y Moral fue una influencia notable. El nombre mismo ya da cuenta de ello. La Sociedad Francesa tenía como objetivo "estudiar los medios -y los medios de todo orden- a llevar a cabo para disminuir en la medida de lo posible la frecuencia de las afecciones venéreas y de la sífilis en particular». Además, buscaba «enseñar al público por publicaciones, folletos, conferencias lo que es necesario saber acerca de peligros y medios de contagio venéreos y no venéreos» («But et espérances», 1901, pp. 6-8).

La Sociedad Mexicana de Profilaxis Sanitaria y Moral fue formada «a fin de luchar contra la propagación de las enfermedades venéreas, especialmente la sífilis y la blenorragia, y contra los males sociales e individuales de que son causa o efecto» («Reglamento», 1909, p. 5). En su lucha, la Sociedad promovería conocimientos y prácticas sugeridas desde la moral y la medicina para combatir aquellas «inmoralidades», que dañaban tanto el cuerpo como el alma («La Cruz Blanca se presenta», 1908, p. 1). Después de todo, la Sociedad era la «hija del consorcio de la radiante ciencia y la beneficiosa moral» (Terrés, 1911, p. 2). La medicina "científica», plantearía "la obviedad del conocimiento para prevención»; en tanto que la moral, aun con sus «diferentes criterios», tendería a «la perfectibilidad humana» (Cicero, 1908, p. 2).

El carácter «científico» de la medicina era asumido por los médicos de la Sociedad, quienes, desde una perspectiva positivista, asumían que estos conocimientos eran objetivos y verificables, y a diferencia de moral, no daban cabida a la subjetividad de «diferentes criterios». La "cientificidad» de la medicina, en teoría, haría «obvios» los conocimientos para la prevención. Sin embargo, la distinción entre las consideraciones médicas y las morales no siempre fue clara, y esto llevó a discrepancias entre algunos de los miembros de la Sociedad, por ejemplo, en cuanto a la castidad ¿hasta qué punto era saludable y hasta qué punto un asunto moral? Las recomendaciones médi- 
cas, después de todo, no parecían ser tan obvias y objetivas como los miembros de la Sociedad pretendían, como se verá más adelante.

La Sociedad buscó integrar a representantes de diversas profesiones, corporaciones científicas, hospitales, prensa y gobierno (Carrillo, 2010, pp. 75-76). En las primeras reuniones de la Sociedad Mexicana estuvieron "delegados de las sociedades de Medicina Interna, del Hospital General, 'Pedro Escobedo', de Estudios Sociales, del Colegio Militar, de los hospitales 'Juárez', Militar y 'Morelos', y de los periódicos El Diario y El Imparcial». Además, hubo delegados de la Secretaría de Instrucción Pública y Bellas Artes, y el canónigo Vicente de P. Andrade contestó favorablemente la invitación. La Sociedad contó con médicos, abogados, profesores, periodistas, militares e ingenieros. El doctor José Terrés fue su presidente y el experto en sifilografía, Ricardo Cicero, su vicepresidente. A un año de haberse constituido, la Sociedad tenía 57 miembros activos ("La Sociedad», 1908, p. 2).

\section{LA CRUZ BLANCA Y EL AMIGO DE LA JUVENTUD}

A fin de cumplir su cometido, la Sociedad Mexicana de Profilaxis procuró la difusión de conocimientos, fundamentalmente a través de su periódico mensual La Cruz Blanca. Éste fue publicado de septiembre de 1908 a noviembre de 1912 y en abril de 1913 cambió su nombre por El Amigo de la Juventud, que dejó de editarse en agosto de 1923.

El nombre del periódico La Cruz Blanca, de acuerdo con sus redactores, "revela su objeto, al par que los procedimientos que se propone emplear para realizarlo». Su objetivo era "combatir las inmoralidades, que dañan el alma tanto como el cuerpo» y para ello "nada hay tan eficaz como llevar a todos los espíritus las conclusiones clarísimas de la ciencia, que, comprobando la fatalidad de los resultados nocivos de determinados actos, nos obliguen a rechazar el mal por los peligros con que amenaza y a amar el bien y defenderlo por la utilidad que ofrece» ("La Cruz Blanca se presenta», 1908, p. 1).

La Cruz Blanca formaba parte de lo que González Urueña llamaba y asumía como «la misión apostólica» de la Sociedad (González, 1909, p. 1). Esta idea de «evangelizar», "predicar» y «redimir» mediante el discurso higiénico y "científico» no era extraña para los médicos de la época, y seguramente los demás miembros de la Sociedad también entendieron así su labor $^{3}$. De esta manera, el nombre del periódico alu- día a un símbolo de la evangelización y a un color que fácilmente puede relacionarse con la pureza. Después de todo, la moral era una de las preocupaciones centrales de la Sociedad, y lejos de que los miembros de la Sociedad la vieran como opuesta al conocimiento médico, consideraban que la moral podía coadyuvar a la prevención de las enfermedades venéreas.

La Cruz Blanca tenía de cuatro a seis páginas impresas en tres columnas y sin imágenes (Imagen 1).En ellas se publicaban documentos de la Sociedad como dictámenes, discursos o trabajos presentados en las sesiones. Además, formaban parte de este periódico artículos de temas relacionados con la prevención de enfermedades venéreas como la educación sexual, la moral, los peligros de la charlatanería, la legislación sanitaria del matrimonio, el contagio nutricio, entre otros. La mayoría de estos textos fueron de la autoría de los miembros de la Sociedad, pero La Cruz Blanca también tradujo y publicó algunos artículos de la prensa extranjera. Este periódico buscaba llevar más allá de las sesiones de la Sociedad los debates que a nivel mundial se tenían sobre la lucha antivenérea.

Imagen 1. Portada del periódico La Cruz Blanca, noviembre de 1908

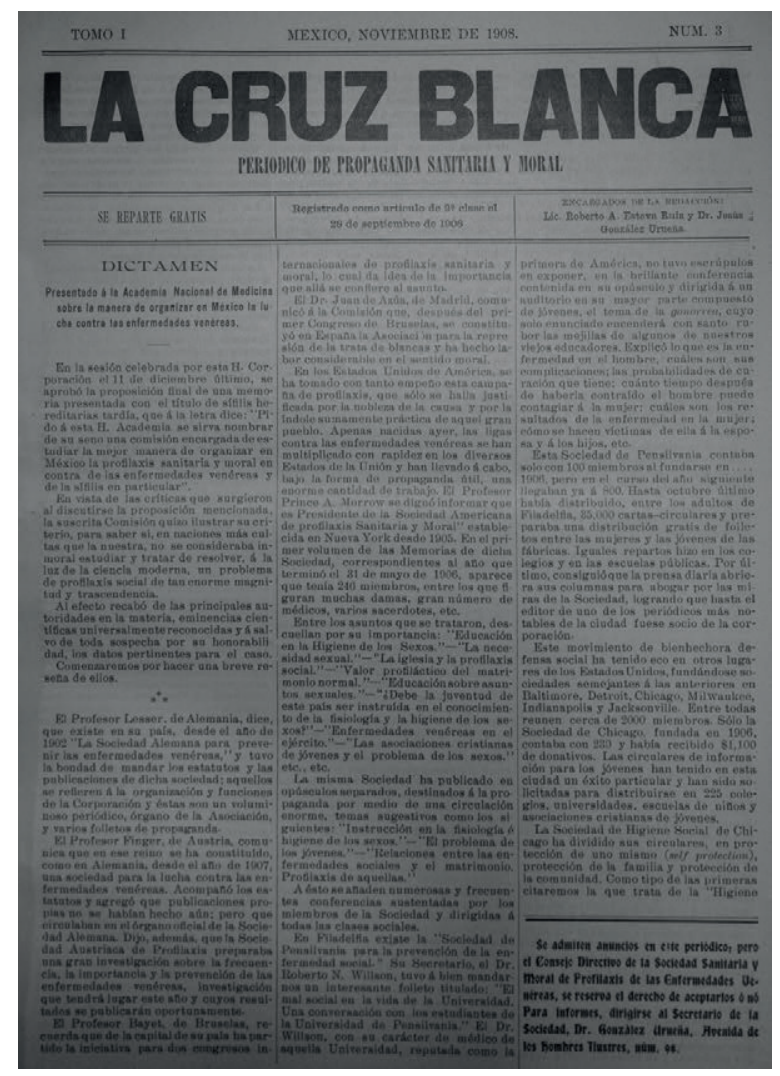


En las páginas de La Cruz Blanca quedaron plasmadas diversas formas de entender la sexualidad y lo que ésta debía ser, de acuerdo con criterios considerados saludables, tanto desde la «ciencia» como desde la moral $^{4}$. En el periódico de la Sociedad quedó de manifiesto que las opiniones de sus miembros no siempre fueron unánimes. Aun si alegaban tener fundamentos objetivos y «científicos», la distinción entre moral y medicina "científica» no era del todo clara en los argumentos esgrimidos para definir lo que era saludable. Un ejemplo de ello es la polémica sobre el problema de la prostitución que sostuvieron el periodista y criminólogo Carlos Roumagnac y el médico Eduardo Lavalle Carvajal (Benavides, 1912, p. 1; Estrada, 2005, pp. 117-144). Este último estaba a favor de la reglamentación de la prostitución, pues consideraba que era una "mala necesidad» que debía regularse para satisfacer el instinto sexual masculino y favorecer el orden social. Roumagnac, en cambio, fue crítico de esta visión y partidario de la prohibición de prostitución (Estrada, 2005, p. 123). Las perspectivas de ambos tenían que ver con la forma en que entendieron la sexualidad y la castidad: según Lavalle, la anatomía «externa» de los genitales masculinos hacía que estuvieran expuestos a la excitación, haciendo que el instinto fuera incontenible, a diferencia de los genitales femeninos, que eran «internos»; para Roumagnac, la sexualidad masculina podía controlarse y la castidad podía ser saludable tanto para mujeres como para hombres (Estrada, 2005, 125-133).

Otros médicos de la Sociedad defendieron la idea de que la castidad masculina no sólo no afectaba las funciones fisiológicas y genésicas de los varones, sino que era quizá la forma más efectiva de prevenir las enfermedades venéreas. En opinión de algunos, la «represión de las pasiones» acabaría por «dar muerte al dragón» (García, 1909, p. 3). Por ello, no faltaron los llamados a «educar en castidad» (Carrillo, 2010, p. 75), a fin de enseñar a la juventud que «mientras no Ilegue al tálamo nupcial hay enormes ventajas, tanto físicas como morales en conservarse casto, o al menos excesivamente continente» (Cicero, 1908, p. 2).

La instrucción de los jóvenes acerca de la prevención de las enfermedades venéreas fue un tema central en las publicaciones de La Cruz Blanca. Las opiniones al respecto tampoco fueron unánimes, pues mientras algunos abogaban por la utilidad de la educación sexual en las escuelas, otros expresaron que tal información resultaría contraproducente (Carrillo, 2010, pp. 75-76). El profesor Manuel Velázquez Andrade fue un entusiasta partidario que publicó artícu- los no sólo de su autoría, sino también traducciones de la Asociación Americana de Higiene Social y la Asociación Alemana para el Mejoramiento de las Madres, que apoyaban la educación sexual en las escuelas. Velázquez consideraba que era mejor instruir a los jóvenes en las aulas, pues de todas formas no se librarían de ser «iniciados» por "medios inconducentes». Para ello era necesario que los maestros tuvieran una preparación adecuada, en la que podía colaborar la Sociedad Mexicana de Profilaxis. Los temas que debían enseñarse eran: higiene personal (continencia sexual y cuidados del cuerpo), moral social (peligros para la colectividad, la sociedad y la raza), e historia natural (botánica y zoología) (Velázquez, 1911, p. 3).

La Cruz Blanca también publicó un artículo del doctor Lavalle Carvajal que cuestionaba la «educación sexual precoz» con la que los niños "genitalmente prematuros» llegaban a ser "artificialmente madurados». Consideraba que las enseñanzas sobre la reproducción en plantas y animales serían inútiles, pues las «imaginaciones infantiles» jamás llegarían a "la rebuscada asociación de ideas». Los padres ignorantes, y los maestros no mejor preparados, no serían aptos para tratar estos temas. Por ello, se congratulaba de que en México, por entonces, no había siquiera intentos de llevar a cabo esa educación. Proponía en cambio, enseñanzas «indirectas», «presexuales», más relacionadas con el "entrenamiento de la voluntad infantil» y el "dominio sobre el yo» (Lavalle, 1912, pp. 1-3).

La Cruz Blanca se repartía de manera gratuita a fin de que su difusión fuera lo más amplia posible. Las fuentes consultadas no nos aportan información acerca de dónde era repartida, tampoco de su tiraje ni de sus lectores; sin embargo, en el mismo periódico hubo expresiones de optimismo acerca de la aceptación de esta publicación. Once meses después del primer número de La Cruz Blanca, González Urueña escribió que «los primitivos temores» sobre «la misión apostólica» de la Sociedad estaban desapareciendo. Por ello, consideraba que «esta primera etapa de la existencia de nuestra publicación, la señalamos gustosos como una nota de triunfo y nos servirá de aliento para proseguir adelante» (González, 1909, p. 1). La publicación continuó y en marzo de 1910, José Terrés afirmó: «... el periódico de la Sociedad es recibido en todas partes sin recelo, y algunos números han circulado entre señoritas» (Terrés, 1910, p. 2).

Tanto los comentarios de Terrés y González Urueña como el hecho de que la Sociedad siguió con su periódico hasta 1923 sugieren que esta publicación contó 
con un grupo de lectores que hacían viable su continuidad. Es difícil conocer a estos lectores, pero seguramente entre ellos estaban los mismos miembros de la Sociedad y algunos profesionales interesados en el tema. También podría deducirse de la afirmación de Terrés que La Cruz Blanca tenía un público fundamentalmente masculino y que la circulación del periódico entre las señoritas era más bien excepcional. No obstante, La Cruz Blanca presentaba contenidos destinados a las mujeres, y a ellas dedicó el número 6, publicado en 1909. Dicho número tenía el propósito de «circular... de preferencia entre las damas, con el objeto de darles una idea de la agrupación y solicitar su valioso concurso en la obra de regeneración que ha emprendido [la Sociedad]» (Márquez, 1909, p.1). Se pedía a las mujeres que, como madres, recomendaran a sus hijos varones que se acercaran a la Sociedad y siguieran sus enseñanzas (Márquez, 1909, p. 1).

Otro de los artículos de este número fue escrito por una mujer, la doctora Soledad de Régules, quien trató el tema de "los peligros del beso». En él instaba a sus lectoras a no besar en el saludo, pues así se podían transmitir microbios y enfermedades infecciosas como la gripa o la tuberculosis (De Régules, 1909, pp. 1-2). Sin embargo, no menciona las enfermedades venéreas, ni la posibilidad de que una persona presentara lesiones sifilíticas en la boca. Esta omisión, así como el restringido papel atribuido a las mujeres en la lucha antivenérea por este número de La Cruz Blanca, seguramente tuvieron que ver con un gran interés por «no herir [la] delicadeza, aun en los temperamentos más escrupulosos» (Márquez, 1909, p.1). Es factible, además, que los autores de estos textos asumieran que los varones, ya fuera por cuestiones "anatómicas» o morales, fuesen más propensos al acto sexual y a contraer enfermedades venéreas, y que por tanto, era a ellos a quienes había que brindar información más detallada y específica sobre tales males.

La forma entender el papel de las mujeres en la prevención de las enfermedades venéreas tampoco fue unánime entre los miembros de la Sociedad. La Cruz Blanca publicó un artículo "para las señoras y las jóvenes» que advertía sobre los peligros de las relaciones sexuales «ilícitas», en particular las enfermedades venéreas y el embarazo. Explicaba los síntomas de la sífilis y la gonorrea en las mujeres y afirmaba que «las jóvenes que se entregan al amor libre enferman casi sin excepción». Aconsejaba no hacer caso a celestinas, ser precavidas con el consumo de bebidas embriagantes y, en caso de "entregarse» a un hombre, estar atentas a posibles síntomas y bus- car un médico a la menor sospecha de de enfermedad («Para las señoras y las jóvenes», 1911, pp. 3-4). Otro de sus artículos estaba dirigido a las cocineras, a quienes su autor explicaba la posible transmisión de las enfermedades venéreas por la saliva y recomendaba desinfectar hirviendo en agua los utensilios de cocina (Benavides, 1911, p. 3).

La publicación de La Cruz Blanca se vio afectada por la lucha armada de la Revolución mexicana. Aunque hubo esfuerzos importantes de los miembros de la Sociedad para continuar con la edición de todos los números, La Cruz Blanca tuvo que suspender algunos meses. En medio de las hostilidades de la guerra, en abril de 1911 un grupo de estudiantes de medicina y enfermería crearon una asociación Ilamada «La Cruz Blanca Neutral» que se encargaría de atender a heridos, independientemente de su ideología (Carrillo, 2002, p. 25). Para evitar cualquier confusión entre el periódico de la Sociedad de Profilaxis Sanitaria y Moral y esta nueva asociación, en abril de 1913 tal publicación cambió su nombre por El Amigo de la Juventud (Amigo de la Juventud, n. 1, 1913, p. 3).

El título no fue el único cambio que tuvo el periódico de la Sociedad. La redacción y la presentación de El Amigo de la Juventud también fueron modificadas. Estos cambios se vieron influenciados por las tendencias en la forma de hacer propaganda desarrolladas en las primeras décadas del siglo XX. La publicidad comercial y la propaganda política difundida durante la Primera Guerra Mundial plantearon ideas novedosas acerca de cómo dirigir la opinión y el actuar de la población (Thomson, 1996, pp. 253-272). Las campañas sanitarias en diversas partes del mundo se nutrieron de estas experiencias y no dudaron en incorporar nuevas técnicas y en hacer uso de todos los medios de comunicación disponibles.

En el caso de la prevención de las enfermedades venéreas, la atención se centró primero en los ejércitos, pues la guerra evidenció que entre los jóvenes había una «porción inmensa, inútil para acudir al Ilamado de la patria», porque los cuerpos de los «aparentes Hércules» estaban «invadidos por la peste roja (la sífilis)»(Castillo, 1925, p. 18). Un ejemplo de ello fue la campaña promovida en el ejército norteamericano por la Commission of Trainning Camp Activities, que fue ampliamente conocida en México (Brandt, 1985).

El Amigo de la Juventud solicitó para su publicación «artículos literarios o poesías que contribuyan a darle amenidad, dando preferencia a los que sus 
lectores tengan la bondad de remitirle». Para acercarse a su público, el periódico incluyó también una sección de consultas. Esta sección permitió que mujeres y varones, de manera anónima, buscaran respuesta a diversas inquietudes relacionadas, por lo general, con temas sexuales o con las actividades de la Sociedad. En ocasiones se publicaron las cartas, en otras, sólo las respuestas. El Amigo de la Juventud respondió a "Estudiante», quien preguntó por las sesiones de la Sociedad; agradeció a Darío N., quien les aconsejaba «influir» en los legisladores para facilitar la prevención; y reiteró la preocupación de la Sociedad por el problema de la prostitución, ante los reproches del señor B. S por «no ocuparse» de la supresión de la Inspección de Sanidad. Otros temas más personales fueron expuestos ( Sección de Consultas», 1913, 5, p. 3; "Sección de Consultas», 1913, 8, p. 3; "Sección de Consultas», 1914 , p. 3). La señora M. de H. escribió intranquila porque las "perturbaciones de salud» de sus hijos estuvieran relacionadas con la abstinencia sexual, como lo había afirmado un médico, que El Amigo de la Juventud no dudó en llamar «charlatán» («Sección de Consultas», 1913, 3, p. 2). "Preocupada», una señorita de 28 años, temía que sus malestares físicos que la ponían "fea» se debieran a que no estaba casada ni deseaba hacerlo. Aunque según El Amigo de la Juventud la "vida de la mujer casada (suponiéndola higiénica) favorece la salud», era posible que estando soltera conservara la salud, pues «la que suprime todas las causas de excitación, no tiene por qué temer malas consecuencias de su abstinencia» ("Sección de Consultas», 1913, 5, p. 3). También escribieron personas angustiadas por la posibilidad de contagio de sífilis, como el señor D. $G$, que temía que las Ilagas en la boca de su hijo, que asociaba al uso de un pito en una "posada», fueran sifilíticas, o "enamorado», quien temía que la viuda con quien iba a casarse estuviera enferma, porque la causa de muerte del esposo había sido sífilis. El Amigo de la Juventud recomendó en estos casos acudir a un médico ("Sección de Consultas», 1914, 11, p. 3; «Sección de Consultas», 1913, 6, p. 3).

El Amigo de la Juventud aumentó su tiraje "por lo menos a cinco mil» (Amigo de la Juventud, n. 1, 1913, p.3). Con este incremento, se dio la posibilidad de ofrecer suscripciones en toda la República, que costaban un peso por año o cinco centavos por número (Amigo de la Juventud, n. 2, 1913, p. 2). Además, aceptó anuncios que no contradijeran sus contenidos, por ejemplo, de talco o consultorios médicos (Imágenes 2 y 3 ).
Con el paso de los años, El Amigo de la Juventud (Imagen 4) incluyó temas generales de higiene que no necesariamente estaban relacionados con las enfermedades venéreas, por ejemplo, los peligros del polvo, las moscas y el chupón para los bebés, entre otros (imagen 4). También incorporó textos breves, frases cortas, fábulas e imágenes. El periódico podría decirse que era precisamente, más «amigable».

Aunque El Amigo de la Juventud se preocupó por presentar la información de una forma más amena que La Cruz Blanca y publicó una mayor variedad de temas, continuó expresando que las enfermedades venéreas eran un problema tanto sanitario como moral. El Amigo de la Juventud recomendaba acudir a un médico calificado en caso de enfermedad, y algunos artículos pusieron énfasis en la castidad y el control de la voluntad como medios eficaces de prevención. De acuerdo con uno de los textos publicados, era común ver a muchachas «pintarrajeadas... con el cabello mordiscado, con vestidos escandalosos, que se consagran sólo al coqueteo, más o menos embozado». Y los varones, en no mejores condiciones, solían estar bajo el «yugo de tontos prejuicios», convencidos de que "el hombre debe dar satisfacción a todos sus sentidos». Por ello, para evitar que «la juventud siga aniquilándose y prostituyéndose», recomendaba la enseñanza teórica y práctica de la religión y la moral (González, 1923, p. 1).

Cuando comenzó a publicarse El Amigo de la Juventud, la Sociedad tuvo la ventaja de contar con los recursos económicos donados por la Sociedad Mexicana de Medicina Interna, que entonces se extinguió. Sin embargo, esta buena nueva llegó a la Sociedad en un momento de conflictos políticos y militares provocados por el derrocamiento del presidente Francisco I. Madero en febrero de 1913, durante la llamada Decena Trágica. A pesar de ello, la Sociedad no desistió en su labor. «Si es cierto que un tremendo espasmo político nos ha conducido a una condición muy semejante al caos social, no por eso la Sociedad de Profilaxis ha paralizado su obra que es de aquellas que son necesarias mientras viva la unidad humana, el individuo, a quien equilibrar, moralizar y robustecer» (Durán, 1914, p. 1).

\section{OTRAS FORMAS DE PROPAGANDA}

Además de su periódico, la Sociedad Mexicana de Profilaxis Sanitaria y Moral publicó varios folletos. Uno fue la traducción de un texto del prestigioso sifilógrafo francés Alfred Fournier titulado «Para nuestros hijos cuando tengan 18 años» (1909) y otro folleto, que no pude consultar, «Sobre la educación sexual de las adolescentes» que estaba dirigido a las madres de familia y a las maestras (1913) (Durán, 1914, p. 1). 
Imagen 2. El Amigo de la Juventud, febrero de 1914

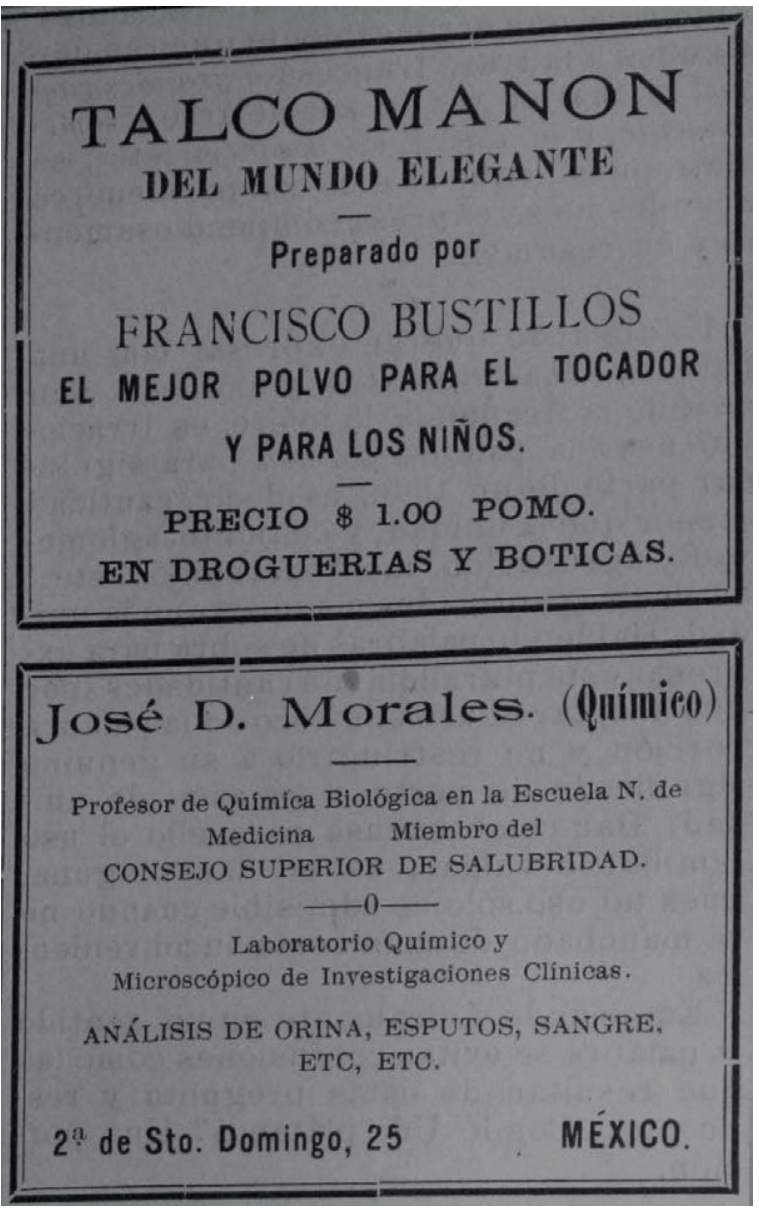

La traducción del texto de Fournier estuvo a cargo del doctor Everardo Landa. El tiraje de 500 ejemplares se agotó y la Secretaría de Guerra y Marina se encargó de imprimir más (González, 1909, p. 2). Esta versión del texto también fue difundida en Venezuela con la anuencia de la Sociedad Mexicana de Profilaxis. De acuerdo con su autor, "Para nuestros hijos cuando tengan 18 años» contenía información acerca de las enfermedades venéreas: síntomas, complicaciones, pronóstico, importancia del tratamiento, consecuencias individuales y familiares, y estadísticas. Aunque de acuerdo con Fournier el folleto tenía «sólo consideraciones médicas», también advertía sobre la «provocación femenina» y los peligros de las prostitutas, sobre todo de las clandestinas. Asimismo, planteaba que si el temor a la sífilis podía constituir un «principio de sabiduría», también lo serían la moral, la religión y el respeto a sí mismos, a la mujer y a los futuros hijos. Finalmente, si la "atracción de los sentidos" ganaba y llevaba a «la fatalidad», aconsejaba buscar ayuda de
Imagen 3. El Amigo de la Juventud, octubre de 1921

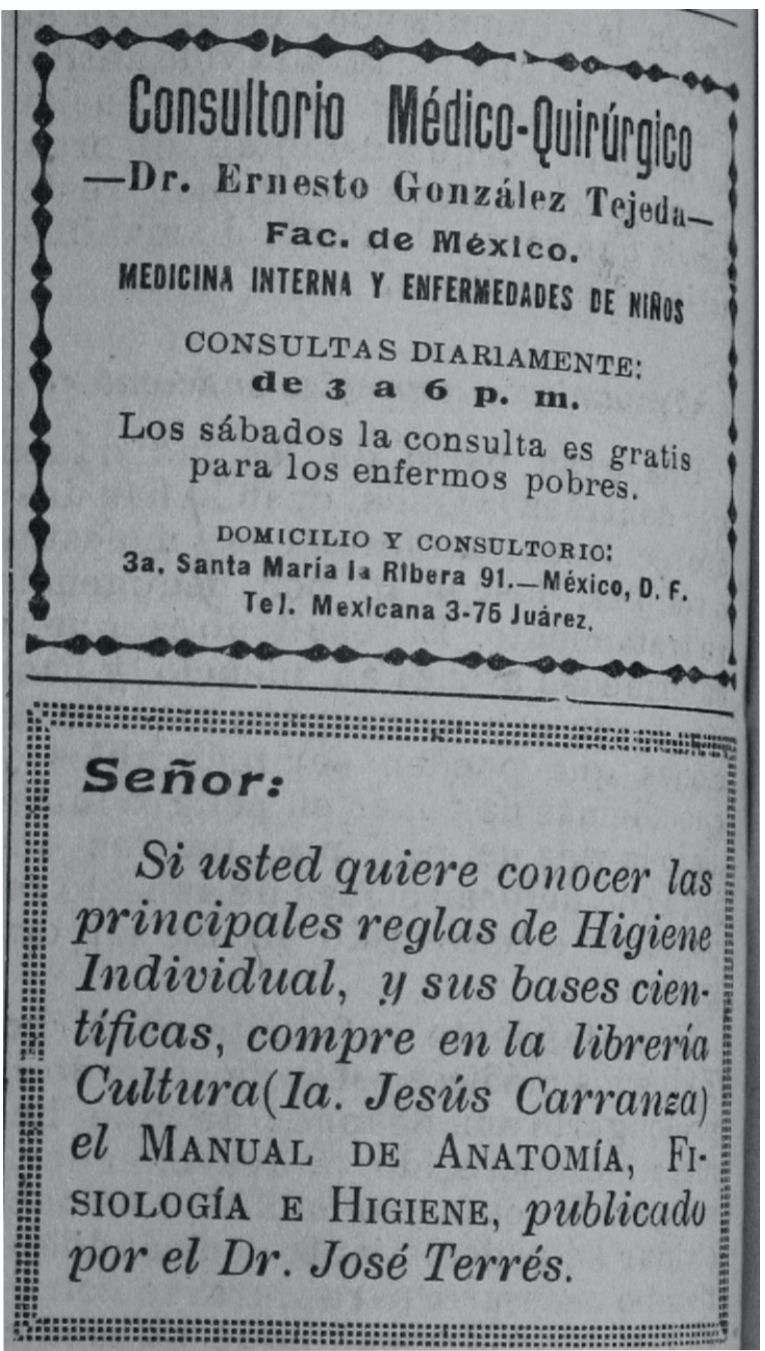

la familia. El doctor Landa, convencido de la utilidad de esta información, consideró la posibilidad de cambiar el título del folleto y dedicarlo a jóvenes de 15 años y no de 18, pero decidió respetar el texto original (Fournier, 1912).

La Sociedad también procuró la divulgación de conocimientos a través de conferencias que algunos de sus miembros daban en escuelas de la ciudad de México, como la Nacional de Jurisprudencia, la de Ingenieros, la Nocturna para obreros y la Industrial «José María Chávez». Entre los temas tratados en las conferencias estaban los peligros de las enfermedades venéreas y las formas de evitarlos. La Sociedad solicitó que los médicos inspectores de la Secretaría de Instrucción Pública y Bellas Artes dieran conferencias de higiene sexual, por lo que se acordó que estos hablarían de «tan importante asunto» en algunos de los 
Foto 4 Portada de El Amigo de la Juventud, mayo y junio de 1923

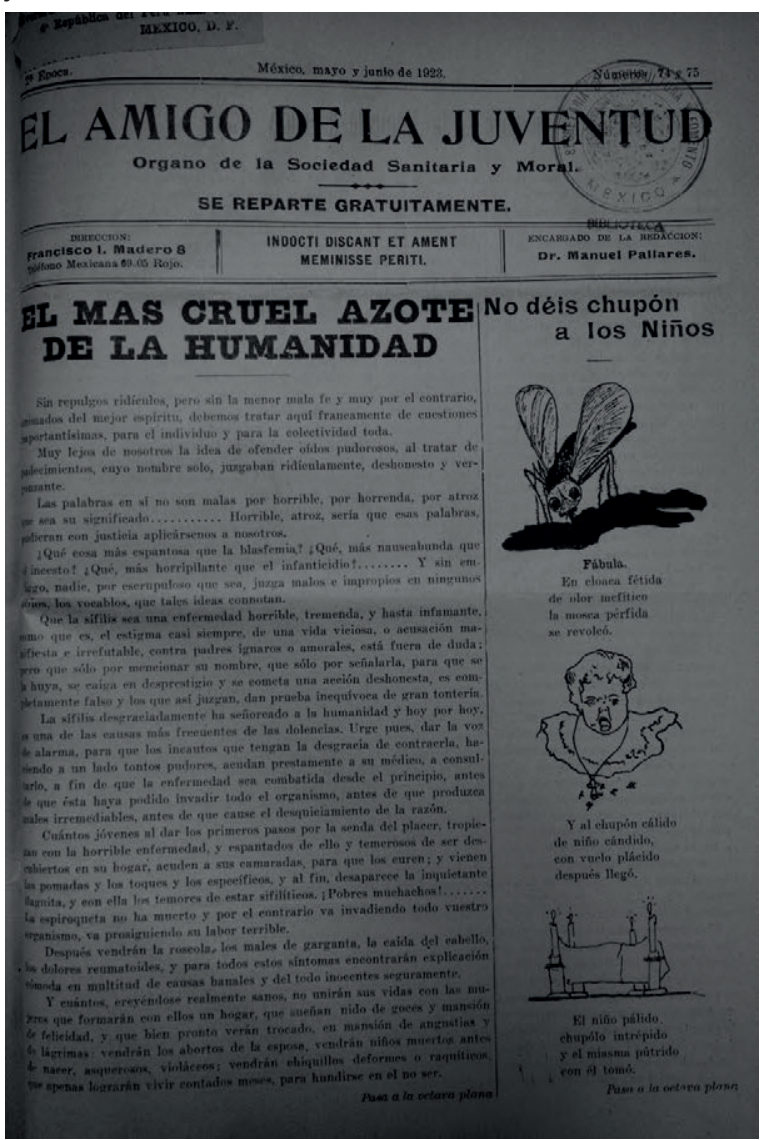

planteles, "una vez al año» («Notas breves», 1911, p. 4). También se convino que los médicos inspectores hablarían de la manera de proteger a las nodrizas del contagio, en aquellas escuelas que juzgaran oportuno (Terrés, 1911, p. 2).

Además de sus publicaciones y de las conferencias, la Sociedad promovió la creación de dispensarios para la atención gratuita de los enfermos venéreos. Un año después de la fundación de la Sociedad, la Junta Española de Beneficencia ya contaba con un dispensario y los médicos del Hospital de Jesús y Béistegui se manifestaban dispuestos a seguir el ejemplo de la Junta Española (González, 1909, p. 2). Los dispensarios serían útiles no sólo para la curación, sino como «centros de acción y efectiva propaganda» (Sánchez, 1908, p.1).

El valor de los dispensarios como parte de la lucha antivenérea estaba fuera de dudas, pero hubo discrepancias en la opinión de los miembros de la Sociedad respecto de la participación del gobierno en su establecimiento. Para los doctores Vicente Sánchez Gavito, Francisco Bulman y Samuel García la participación del gobierno era necesaria, pero no faltaron quienes dentro de la misma Sociedad criticaban la inactividad de ésta por «esperar que todo lo resolviera el gobierno» (García, 1909, p. 4). Pero aun quienes consideraban que el gobierno debía formar parte de la lucha antivenérea emprendida por la Sociedad, manifestaban que el «poder público» debía ser sólo un apoyo. Así, Samuel García opinaba que el gobierno:

debe ser, no la única o la principal palanca con que mover tan pesado carro, pero sí un socio protector, el primero, por ser, por su naturaleza, el fiel guardián de todos los intereses sociales. Y todo este trabajo es preciso que lo hagamos todos con arreglo a nuestras fuerzas, sin pretender que una parte sola haya de reportar el mayor peso (García, 1909, p. 5).

\section{OBSTÁCULOS Y CRÍTICAS}

A pesar de los esfuerzos, la Sociedad enfrentó diversos obstáculos. Uno de ellos fue que el presupuesto fue casi siempre limitado pues, salvo algún caso excepcional, los ingresos provenían de las cuotas pagadas por sus miembros y de los donativos. Por otra parte, hubo desde el principio fuertes críticas a la labor de la Sociedad, que no asombraron ni desanimaron a sus integrantes. "Lo que sí ha debido sorprender en sumo grado, son los lugares en donde han surgido ciertos enemigos y las armas esgrimidas en contra de la Sociedad, y especialmente de algunos de sus miembros, por creer, falsamente, que ellos eran los únicos que trataban de mejorar los acontecimientos». Entre los miembros de la Sociedad hubo críticos que no tardaron en desertar (Terrés, 1911, p. 2). Aunque la Sociedad daba cabida a distintas opiniones, incluso contradictorias, es posible que se presentaran diferencias ideológicas que llevaran a algunos miembros a apartarse de ella. También es factible que las desavenencias se debieran a la inconformidad por las formas de organización de la Sociedad. Como se verá más adelante, hubo en años posteriores médicos que cuestionaron el protagonismo de Terrés en la Sociedad («Por la Sociedad», 1922, p. 2).

Aunque la Sociedad contó con el apoyo de diversas instituciones y logró reunir a personas de distintas profesiones, no faltó el escepticismo de quienes pensaban que sus acciones podían traer más perjuicios que beneficios. Así, la Sociedad, «nacida entre la desconfianza y las zozobras tuvo por vaticinio un anatema 
de muerte, tachándose de inmoral y corruptora su labor» (González, 1909, p. 2). No obstante las críticas, la Sociedad no desistió en su lucha antivenérea y un año después de haber sido fundada, sus miembros se congratulaban de sus labores:

\author{
Loor a la falange distinguida, \\ sin anhelar ni vítores, ni palmas, \\ por amor a la ciencia y a la Vida, \\ busca curar la vergonzosa herida, \\ ese mal de los cuerpos y las almas; \\ vuestra noble misión es salvadora, \\ es en alivio del dolor humano; \\ después de la contienda bienhechora \\ veréis, en un futuro no lejano, \\ a la familia humana redimida \\ de su carga de oprobio y desventura; \\ hoy, al mirar la ignominiosa llaga, \\ la humanidad vuestros esfuerzos paga \\ bendiciendo la mano que la cura. \\ Mientras vencéis, falange distinguida, \\ mientras ceñís el lauro a vuestras sienes, \\ yo os mando mis sinceros parabienes, \\ en nombre de la Ciencia y de la Vida
}

(Nájera, 1909, p. 238).

El optimismo de algunos contrastaba con visones más mesuradas sobre el alcance de las actividades de la Sociedad. El profesor David G. Berlanga, quien realizaba estudios sobre psicología y educación en Leipzig, lamentaba que «el problema sexual» en México no tomara el «desenvolvimiento extraordinario y expansivo" que sí tenían los asuntos políticos. A pesar de la importancia y la pertinencia de los trabajos discutidos en la Sociedad, Berlanga consideraba que éstos «no han sido debidamente atendidos por los círculos extraños ni por la prensa». "Parece así, que desgraciadamente los trabajos científicos pasan para nosotros desapercibidos». El problema no sólo era el poco interés mostrado fuera de la Sociedad, sino que las discusiones «no siguen el debido camino para llegar al fin propuesto, de resultados más prácticos e inmediatos». Entre las medidas propuestas por Berlanga estaba la vigilancia de la prensa, del teatro, del cine y de los libros, para que no denigraran "sentimientos elevados». Además, sugería evitar las «relaciones ilegales» y fomentar el «sentimiento de pudor». Para ello, se haría necesaria la participación de autoridades, científicos y prensa (Berlanga, 1909, pp. 1-2).
En el informe de los trabajos realizados en 1921, la Sociedad reconoció que "no son escasas, por desgracia, las personas que dudan del provecho que de nuestra agrupación reciben las clases sociales, no falta quien asegura la esterilidad de nuestros trabajos, calificándoles de poco 'prácticos'». A pesar de ello, la Sociedad se expresaba "triunfante» en su décimo cuarto año de existencia («Informe», 1922, p. 3).

\section{EL FINAL DE LA SOCIEDAD MEXICANA DE PROFILAXIS}

Las labores de la Sociedad Mexicana de Profilaxis continuaron, pero con el tiempo el entusiasmo de algunos de sus integrantes fue menguando. Esto se vio reflejado en la cantidad de trabajos presentados durante sus sesiones, que para 1922 apenas Ilegaron a tres, a diferencia del año anterior en que hubo once. "Diversos factores contribuyeron a la disminución de los trabajos científicos, y a la escasa concurrencia que hubo en las sesiones; ya, penoso es decirlo, nuestra apatía» ( Informe», 1922, p. 3). Para agosto de 1922 la directiva de la Sociedad planeaba una reunión extraordinaria «con el fin de ver cómo se inyecta nueva savia a nuestra Sociedad, que desgraciadamente como toda obra buena, está condenada a desaparecer, si los asociados y la sociedad en general, no le presta toda la ayuda necesaria» («Por la Sociedad», 1922, p. 2).

La Sociedad Mexicana Sanitaria y Moral se extinguía. ¿A qué se debía la creciente apatía en su seno? Algunos de sus miembros la atribuyeron a la frecuencia de las sesiones (una mensual), otros a la falta de propaganda y anuncios de sus reuniones, y otros más a que el lugar de reunión no era adecuado. Para entonces, la Sociedad se congregaba en la casa del doctor José Terrés (5a de Donceles 115), lo que:

no acomoda al núcleo numeroso de médicos; que juzgan que la Sociedad está sirviendo sólo de pedestal para encumbrar al maestro; que no acomoda y que intimida a los no médicos, que antes asistían a nuestras reuniones, y que ahora no se atreven a penetrar a la casa del Dr. Terrés, temerosos de su seriedad, de su carácter seco, y desconociendo su afabilidad y amabilidad en el trato íntimo («Por la Sociedad», 1922, p. 2).

A pesar de estos señalamientos, por acuerdo de la mayoría de sus integrantes, la Sociedad decidió continuar con las reuniones mensuales en la casa del doctor Terrés («Por la Sociedad», 1922, p. 4). Los problemas económicos que enfrentaba la Sociedad seguramente fueron un factor importante en la 
decisión. La misma ANM tenía dificultades y en la década de 1920 sufrió algunos desalojos y cambió varias veces su domicilio, estableciéndose en diferentes lugares, entre ellos en locales de la Escuela de Medicina y de la Asociación Médica Mexicana (Fajardo, 2014, pp. 119-20).

A los problemas económicos y las divisiones internas en la Sociedad se sumó el hecho de que algunos de los médicos más entusiastas de esta Sociedad tuvieron que alejarse parcial o totalmente de ella. El doctor José Terrés, quien «durante algunos años fue el alma de dicha sociedad» (AANM, numerario \#137), enfermó en 1921 y finalmente falleció el 3 febrero de 1924 (Fajardo-Dolci, 1999, pp. 219-225). Jesús González Urueña, gran promotor de la Sociedad, se consagró a estudiar la lepra y fue designado director del Instituto de Higiene en 1925. Everardo Landa, uno de los redactores del periódico de la Sociedad, pasó a formar parte del Departamento de Salubridad Pública.

La Sociedad Mexicana de Profilaxis Sanitaria y Moral llegó a su fin y El Amigo de la Juventud publicó su último número en agosto de $1923^{5}$. Sin embargo, el interés por «el problema sexual» no murió con ella, sino que fue adquiriendo mayor relevancia entre médicos y autoridades sanitarias. El Departamento de Salubridad Pública, que había sido creado en 1917, asumió la lucha antivenérea y la propaganda sanitaria como parte de ella.

\section{CONSIDERACIONES FINALES}

Las enfermedades venéreas fueron percibidas como una amenaza para la sociedad y el futuro de la nación. Aunque no había estadísticas confiables que dieran cuenta de la cantidad de enfermos, los médicos mexicanos asumieron a inicios del siglo XX que la sífilis estaba muy difundida y que había personas no diagnosticadas que silenciosamente contribuían a la propagación de la enfermedad.

Ante esta situación, los médicos de la Academia Nacional de Medicina plantearon que la mejor forma de enfrentar los males venéreos era por medio del estudio y la difusión de conocimientos acerca de los peligros y las formas de prevenir tales patologías, como se había hecho en varios países. La Sociedad Mexicana de Profilaxis Sanitaria y Moral fue la encargada de llevar a cabo las actividades preventivas. Los medios más importantes fueron la publicación de su periódico, de folletos, las conferencias y la atención médica en dispensarios.
Los integrantes de la Sociedad pensaron las enfermedades venéreas en términos de la ciencia médica y la moral. Consideraron que estas no sólo no eran contradictorias, sino que se complementaban. En teoría, la medicina aportaría conocimientos científicos y "objetivos» para la prevención de las enfermedades, y la moral daría diferentes criterios para actuar bien y alcanzar la "perfección». Sin embargo, la distinción entre los argumentos médicos y morales no siempre fue clara y hubo polémicas acerca de lo que podía considerarse saludable. La conveniencia de la castidad, el control sanitario de la prostitución o la educación sexual fueron discutidas sin que los miembros de la Sociedad tuvieran una opinión unánime.

La conjunción de "ciencia» y moral para la prevención de enfermedades venéreas no siempre fue explícita y en ocasiones, quizá, tampoco consciente. No era raro que argumentos que pretendían ser estrictamente médicos y "científicos» tuvieran consideraciones acerca del «deber ser» femenino y masculino. La medicina, aún con sus pretensiones de cientificidad y objetividad, estaba atravesada por ideas, creencias y costumbres de la sociedad en la que se practicaba. Después de todo, la enfermedad no sólo tiene que ver microorganismos, células, tejidos y órganos, sino que involucra toda la complejidad del ser humano.

Las labores de la Sociedad Mexicana de Profilaxis fueron valoradas de distintas maneras. Algunos vieron con optimismo sus actividades, en tanto que otros fueron críticos y señalaron la poca o nula utilidad de las iniciativas de la Sociedad para disminuir la incidencia de las enfermedades venéreas. Más allá de las dificultades y las críticas, los trabajos de la Sociedad no podrían considerarse «estériles», pues contribuyeron a la difundir la idea de que las enfermedades venéreas eran un asunto público que debía enfrentarse más allá de la reglamentación de la prostitución, pues finalmente la sífilis y la gonorrea no estaban confinadas a los burdeles. La administración sanitaria tomaría el protagonismo de la lucha antivenérea a partir de la década de 1920 y en ella participaron médicos que en su momento fueron miembros de la Sociedad Mexicana de Profilaxis Sanitaria y Moral. 


\section{NOTAS}

1. En la época se llamaban "enfermedades venéreas" a enfermedades transmitidas principalmente por la vía sexual, como la sífilis y la gonorrea. Aunque actualmente se prefiere hablar de enfermedades o infecciones de transmisión sexual, en este texto se hablará de enfermedades venéreas, con el objetivo de entender la problemática estudiada en sus propios términos.

2. No he podido localizar mayor información sobre este periódico, pero su nombre hace referencia a la espiroqueta pálida, el agente causal de la sífilis.

3. El doctor Miguel Bustamente, quien participó activamente en la coordinación de los servicios sanitarios, hablaba de

\section{FUENTES PRIMARIAS}

Archivo de la Academia Nacional de Medicina (AANM), expediente de José Terrés, numerario \#137.

Berlanga, David (1909), "El problema sexual”, La Cruz Blanca, I (13), p. 1.

Benavides, Andrés (1911),“Consejos a la cocinera”, La Cruz Blanca, I (25), p. 3.

Benavides, Andrés (1912), "Informe que rinde el Srio. de la Sociedad de Profilaxis Sanitaria y Moral en la sesión de aniversario del 10 de enero", La Cruz Blanca, I (28), p. 1.

Bustamante, Miguel (1934), La coordinación de los servicios sanitarios federales y locales como factor de progreso higiénico en México, México, Departamento de Salubridad Pública.

"But et espérances de notre Societé" (1901), Societé Française de Prophylaxie Sanitaire et Morale, I, Rueff editor.

Castillo Nájera, Francisco (1925), “Discurso inaugural”. En Primer Congreso Mexicano de Venereología, México, Talleres Gráficos Editorial.

Cicero, Ricardo (1908), “¿Es útil divulgar los conocimientos relativos a la sífilis y a otras enfermedades venéreas? En caso de respuesta afirmativa ¿cuáles son los conocimientos que se deben divulgar y qué medios deben emplearse para ese fin?", La Cruz Blanca, 1 (2), p. 2.

Cicero, Ricardo (1925), "El papel del médico en la campaña antivenérea". En Primer Congreso Mexicano de Venereología, México, Talleres Gráficos Editorial.

Código Sanitario de los Estados Unidos Mexicanos, México, Imprenta de Eduardo Dublán, 1903.

Coni, Emilio (1922), "Estado actual de la lucha antivenérea en América". En Segundo Congreso Sudamericano de Dermatología y Sifilografía, T. II, Montevideo.

De Régules, Soledad, "Los peligros del beso", La Cruz Blanca, I (6), pp. 1-2. "llevar el evangelio de la salud hasta los últimos rincones de la nación". Bustamante, 1934. En estudios históricos también se ha destacado el interés del gobierno mexicano por "redimir" al pueblo. Véase Bliss, 1999, pp. 1-40.

4. Este fue el caso también de otras sociedades de profilaxis, como Alan Corbin plantea para la Sociedad Francesa de Profilaxis. Corbin, 1990, pp. 265-267.

5. El último número: El Amigo de la Juventud, 2ª época, n. 76 y 77, julio y agosto de 1923.

"Dictamen presentado a la Academia Nacional de Medicina sobre la manera de organizar en México la lucha contra las enfermedades venéreas" (1908), Gaceta Médica, III (5).

“Discurso pronunciado el Sr. Dr. y Lic. Vicente Sánchez Gavito, al inaugurarse la Sociedad Sanitaria y Moral" (1908), La Cruz Blanca, 1 (1), p. 1.

Durán (1914), "Labor de Sociedad Mexicana de Profilaxis Sanitaria y Moral en el año 1913", El Amigo de la Juventud, 13, p. 1.

El Amigo de la Juventud (1913), 1, p. 3.

El Amigo de la Juventud (1913), 2, p. 2.

Ernesto González Tejeda (1923), “iOh tiempos! ¡Oh costumbres!”, El Amigo de la Juventud, 76-77, p. 1.

Fernández Verano, A. (1922), “Acción desarrollada por la Liga Argentina de Profilaxis Social en sus cuatro meses de existencia", En Segundo Congreso Sudamericano de Dermatología y Sifilografía, T. II, Montevideo.

Fournier, Alfredo, Para nuestros hijos cuando tengan 18 años. Consejos de un médico, traducidos por el Dr. Everardo Landa para la Sociedad Mexicana Sanitaria y Moral de las Enfermedades venéreas, Maracaibo, Imprenta El Propio Esfuerzo, 1912.

García, Samuel (1909), “Discurso pronunciado por su autor en la sesión solemne del primer aniversario de la Sociedad Mexicana Sanitaria y Moral", La Cruz Blanca, I (12), p. 3.

García, Samuel (1909), "La moral social y sus relaciones con la moral médica en lo concerniente a la profilaxis contra las enfermedades venéreas", La Cruz blanca, I (5), p. 4.

González Urueña, Jesús (1909), "Sesión de aniversario", La Cruz Blanca, 1 (10), p. 2.

González Urueña, Jesús (1909), “Un año de vida”, La Cruz Blanca, 1 (10), p. 1.

"Informe de los trabajos efectuados por nuestra Sociedad durante el año de 1921" (1922), El Amigo de la Juventud, 58, p. 3. 
"La Cruz Blanca se presenta al público como órgano oficial de la Sociedad Mexicana Sanitaria y Moral de Profilaxis de las Enfermedades Venéreas" (1908), La Cruz Blanca, I (1), p. 1.

La Cruz Blanca (1909), I, (5), p. 5.

"La Sociedad Mexicana de Profilaxis Sanitaria y Moral contra las Enfermedades Venéreas" (1908), Revista Médica, II (2), p. 92.

Landa, Everardo (1925), "Informe”. En Primer Congreso Mexicano de Venereología, México, Talleres Gráficos Editorial.

Lavalle Carbajal (1912), “Educación sexual precoz”, La Cruz Blanca, I (31), pp. 1-3.

Márquez San Juan, Manuel (1909), "A nuestros lectores", La Cruz Blanca, I (6), p. 1.

Nájera, Francisco (1909), “A la Sociedad Mexicana Sanitaria y Moral en el primer aniversario de su fundación", Revista Médica, III (5), p. 238.

“Notas breves" (1911), La Cruz Blanca, I (26), p. 4.

“Para las señoras y las jóvenes” (1911), La Cruz Blanca, I (24), pp. 3-4.

\section{BIBLIOGRAFÍA}

Bliss, Katherine (1999), "The Science of Redemption: Syphilis, Sexual Promiscuity and Reformism in Revolutionary Mexico City", Hispanic American Historical Review, 70 (1), pp. 1-40.

Brandt, Allan (1985), No Magic Bullet. A Social History of Venereal Disease in the United States since 1880, New York/ Oxford, Oxford University Press.

Carrillo, Ana María (2002), "El surgimiento y desarrollo de la participación federal en los servicios de salud". En Fajardo Ortiz, Guillermo; Carrillo, Ana María; Neri Vela, Rolando (coords.), Perspectiva histórica de atención a la salud en México, 1902-2002, México, OPS/UNAM/Sociedad Mexicana de Historia y Filosofía de la Medicina.

Carrillo, Ana María (2005), “¿Estado de peste o estado de sitio?: Sinaloa y Baja California, 1902-1903", Historia Mexicana, LIV (4), pp. 1049-1103.

Carrillo, Ana María (2008), “Guerra de exterminio al fantasma de las costas: la primera campaña contra la fiebre amarilla en México, 1903-1911". En Agostoni, Claudia (coord.), Curar, sanar y educar. Enfermedad y sociedad en México, siglos XIX y XX, México, IIH-UNAM/BUAP, pp. 221-256.

Carrillo, Ana María (2010), "Control sexual para el control social: la primera campaña contra la sífilis en México", Espaço Plural, XI (22), pp. 65-77.

Estrada, Rosalina (2005), "La inevitable lujuria masculina, la natural castidad femenina". En Cházaro, Laura y Estrada, Rosalina (eds.), En el umbral de los cuerpos. Estudios de antropología e historia, México, COLMICH/BUAP, pp. 117-144.
"Por la Sociedad Mexicana Sanitaria y Moral de Profilaxis de las enfermedades venéreas" (1922), El Amigo de la Juventud, 65, p. 2.

"Reglamento de la Sociedad Mexicana Sanitaria y Moral de Profilaxis de las Enfermedades Venéreas" (1909), La Cruz Blanca, I (5), p. 5.

"Sección de Consultas", 1913, El Amigo de la Juventud, 3, p. 2.

“Sección de Consultas" (1913), El Amigo de la Juventud, 5, p. 3.

"Sección de Consultas" (1913), El Amigo de la Juventud, 6, p. 3.

"Sección de Consultas" (1913), El Amigo de la Juventud, 8, p. 3.

"Sección de Consultas" (1914), El Amigo de la Juventud, 11, p. 3.

“Sección de Consultas" (1914), El Amigo de la Juventud, 13, p. 3.

Terrés, José (1911), “Discurso pronunciado por su autor en sesión solemne de 10 de enero del corriente", La Cruz Blanca. I (20), p. 2.

Terrés, José (1910), “Nuevo consejo directivo", La Cruz Blanca, I (14), p. 2.

Velázquez Andrade, Manuel (1911), “El problema sexual en la escuela", La Cruz Blanca, p. 3.

Fajardo-Dolci, Germán (1999), et al., "El doctor José Terrés y su tiempo", Revista Médica del Hospital General de México, 62 (3), pp. 219-225

Fajardo, Guillermo (2014), "La Academia Nacional de Medicina en el México Posrevolucionario: 1917-1946". En Viesca, Carlos (coord.), La Academia Nacional de Medicina de México. 150 años de actividad innenterrumpida, México, Conacyt, Intersistemas Editores, pp. 105-122.

González Urueña, Jesús (1908), "Sífilis hereditaria tardía", Gaceta Médica de México, 3a Serie, 3 (5), pp. 307-314.

Rodríguez, Martha Eugenia (2013), "La Academia Nacional de Medicina de México (1936-1912)", Gaceta Médica de México, 149 , pp. 569-575.

Thomson, Ellen Mazur (1996), "'The Science of Publicity'”: An American Advertising Theory, 1900-1920", Journal of Design History, 9 (4), pp. 253-272.

Veronelli, Juan Carlos y Veronelli Correch, Magali (2004), Los orígenes institucionales de la salud pública en la Argentina, t. II, Organización Panamericana de la Salud.

Viesca Treviño, Carlos (2014), “La Academia durante el Porfiriato y la Revolución, 1880-1916". En Viesca, Carlos (coord.), La Academia Nacional de Medicina de México. 150 años de actividad innenterrumpida, México, Conacyt, Intersistemas Editores, pp. 77-104.

Zavala, María del Carmen (2007), “El cólera en Michoacán y la federalización de las políticas sanitarias en el siglo XIX", Tzintzun, 46, pp. 39-88. 